\title{
Novel phosphotransferase system genes revealed by bacterial genome analysis - a gene cluster encoding a unique Enzyme $I$ and the proteins of a fructose-like permease system
}

\author{
Jonathan Reizer, Aiala Reizer and Milton H. Saier, Jr \\ Author for correspondence: Milton H. Saier, Jr. Tel: +1 619534 4084. Fax: +1 6195347108. \\ e-mail: msaier@ucsd.edu
}

Department of Biology, University of California at San Diego, La Jolla, CA 92093-0116, USA

\begin{abstract}
Previous publications have demonstrated the presence of a cryptic gene encoding a novel Enzyme I of the phosphoenolpyruvate:sugar phosphotransferase system (PTS). Recent Escherichia coli genome sequencing revealed a gene (PtsA) encoding a new Enzyme I homologue in the 89.1-89.3 centisome region. We have analysed this region, and here describe and characterize open reading frames (ORFs) encoding (1) a fused PTS Enzyme IIIA $\mathrm{F}^{\mathrm{Fu}}$ homologue, (2) a glycerol dehydrogenase, (3) a transaldolase homologue, (4) two PTS IIB Fru homologues, (5) a PTS IIC Fru homologue, and (6) homologues of pyruvate formate-lyase and its activating enzyme. Binary comparison scores, multiple alignments and phylogenetic trees establish the families of proteins to which each of the relevant ORFs belong. Identification of the putative products of this gene cluster leads to the proposal that several of the proteins encoded in this region function in anaerobic carbon metabolism.
\end{abstract}

Keywords: sugar transport, phosphotransferase system, anaerobiosis, glycerol dehydrogenase, pyruvate formate-lyase

\section{INTRODUCTION}

Bacteria take up and concomitantly phosphorylate sugars via a phosphoenolpyruvate:sugar phosphotransferase system (Postma et al., 1993). This system transports dozens of sugars via a chain of phosphoryl transfer proteins that consists of two non-sugar-specific components, Enzyme I (I) and HPr, and three or four protein domains of the sugar-specific Enzyme II complex (Enzymes or domains IIA, IIB, IIC and sometimes IID) (Saier \& Reizer, 1992). The phosphoryl transfer chain of the PTS, regardless of the sugar transported, is as follows:

\section{IIC}

$\mathrm{PEP} \rightarrow \mathrm{I} \rightarrow \mathrm{HPr} \rightarrow \mathrm{IIA} \rightarrow \mathrm{IIB} \rightarrow$ sugar

Of these proteins or protein domains, only the IIC component, the sugar recognition constituent that transports the sugar, is not phosphorylated.

IIA and IIB are cytoplasmic proteins or peripherally

Abbreviations: PEP, phosphoenolpyruvate; PTS, phosphotransferase system. membrane-associated domains of the Enzyme II complex, and IIC is an integral membrane permease. The phylogenies of these protein domains have been characterized in previous publications (Reizer et al., 1991b; Saier et al., 1992; Saier \& Reizer, 1992, 1994b). The characterized fructose-specific and fructose-like Enzyme II complexes exhibit IIA and IIB domains that resemble those of the mannitol-specific Enzyme II complex, but the IIC domains are more divergent (see Reizer et al., 1994a).

In 1987 we published results showing that strains of Salmonella typhimurium that were deleted for the pts genes encoding Enzyme I and HPr could be mutated so as to regain PTS function (Chin et al., 1987). A novel Enzyme I was identified and partially characterized, and it proved to have catalytic properties similar to those of the deleted Enzyme I (S. Sutrina, J. Reizer \& M. H. Saier, Jr, unpublished results). The gene, designated $p t s J$, which when mutated gave rise to expression of this novel Enzyme I appears to encode a transcriptional regulatory protein within the GntR family (Reizer et al., 1991a; Titgemeyer et al., 1994).

Recent operon and genome sequence analyses in Escheri- 
chia coli have revealed that this organism contains numerous genes encoding homologues of recognized sugar-specific PTS proteins (Reizer et al., 1992, 1994a, b; Saier \& Reizer, 1994a, b). In addition, E. coli is now known to possess three HPr-like proteins (Jones et al., 1994; Saier \& Reizer, 1994b; Powell et al., 1995) and as shown in this communication, at least two distinct Enzymes I. The second Enzyme I, described here, is included in a gene cluster encoding proteins probably concerned largely with anaerobic carbon metabolism. Other genes within this region encode a pyruvate formatelyase (Pf) homologue, a homologue of the Pfl activating enzyme, glycerol dehydrogenase, a transaldolase homologue, and genes encoding homologues of the fructosespecific IIA, IIB and IIC domains. Surprisingly, and hitherto unprecedentedly, a fructose IIA-like domain is fused in a single polypeptide chain to the C-terminus of the novel Enzyme I moiety. Further, in contrast to the situation observed for all currently sequenced fructose operons, the IIB and IIC proteins are encoded by distinct genes, and two such IIB-encoding genes are present, probably within a single operon together with the IICencoding gene. In this communication we provide a detailed description of this gene cluster and of the encoded protein products. The results illustrate the structural diversity of the PTS and indicate a new level of functional complexity for this intricate enzyme system.

\section{METHODS}

Computer-aided analyses. All sequence analyses and database searches were performed using the GCG package from the University of Wisconsin (Devereux et al., 1984) and the DNASYSTEM package (Smith, 1988). Comparison scores (expressed in SD) were calculated using the RDF2 program with 100 or 200 shuffles as indicated in the table legends. A value of $6 \mathrm{SD}$ is suggestive of homology whereas a value of $9 \mathrm{SD}$ establishes homology. Construction of phylogenetic trees and estimation of the relative evolutionary distances among members of a protein family were as described by Reizer \& Reizer (1994) using the progressive alignment method of Feng \& Doolittle (1990). Mean hydropathy and mean similarity were calculated using a sliding window of 20 residues. Hydropathy plots were designed according to Kyte \& Doolittle (1982). The calculated mean similarity was an arithmetic mean of all pairwise comparisons.

\section{RESULTS}

\section{Organization and identification of genes in the 89.1-89.3 centisome region of the $E$. coli genome}

Fig. 1 presents the gene structure of the 89.1-89.3 centisome region of the $E$. coli chromosome, recently sequenced as part of the $E$. coli genome project (Blattner et al., 1993). The figure presents (1) the proposed gene designations, (2) the directions of transcription, (3) the nature of the gene products, (4) the functional assignments of the protein products based on homology to previously characterized proteins, (5) the GC contents of the open reading frames (ORFs), (6) the codon adaptation indices (CAI) of the corresponding ORFs, and (7) information regarding the putative intercistronic regions. This region contains nine clearly identifiable ORFs, three of which probably comprise a leftwardly directed operon. orf $f 711$ (pts $A$ ) codes for a 711 amino acid protein that exhibits sequence similarity to Enzyme I of the PTS in its Nterminal domain and to Enzyme IIA ${ }^{\text {Fru }}$ in its C-terminal domain. This protein will hereafter be designated Enzyme $I^{\text {Ani }}$ (IIA-included). orf $f 220$ (talC) encodes a protein (TalC) that falls into the transaldolase family, while orf $f 380$ (gld $A$ ) encodes a glycerol dehydrogenase (GldA) (Truniger \& Boos, 1994). In the rightward direction, a short ORF, orf o109, encodes a serine-rich protein lacking significant sequence similarity to all proteins in the current databases. Following a large intercistronic region of $341 \mathrm{bp}$, orf 0359 ( frw $C$ ) encodes a IIC $^{\mathrm{Fru}}$-like protein (IIC $^{\text {Frw }}$ or FrwC). Fourteen basepairs downstream of orf 0359 is the initiation codon (ATG) for orf 0106 , encoding the first of two IIB $^{\text {Fru-like proteins (here designated }}$ $\mathrm{IIB}^{\text {Frw }}$ or FrwB). Thereafter follow orf 0765 ( $\left.p f D\right)$, encoding a protein homologous to pyruvate formatelyase (PfD), orf o 315 ( $p f C$ ), encoding a pyruvate-formatelyase-activating enzyme homologue (PfC), and orf o113, encoding a second IIB $^{\text {Fru }}$-like protein (IIB ${ }^{\text {Frw' }}$ or FrwD).
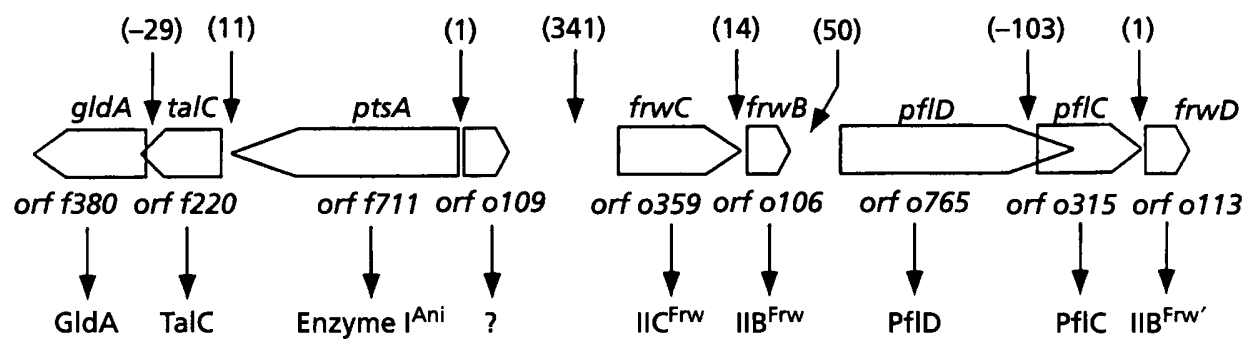

$\begin{array}{lccccccccc}\text { CAl } & 0.46 & 0.36 & 0.39 & 0.19 & 0.40 & 0.47 & 0.35 & 0.28 & 0.30 \\ \mathrm{GC}(\mathrm{mol} \mathrm{\%}) & 54 & 54 & 56 & 56 & 54 & 50 & 53 & 56 & 50\end{array}$

Fig. 1. Genetic map of the GIdA-Enzyme IAni-Frw PTS region in $E$. coli. The map shows the proposed gene assignments for the DNA region that comprises nine ORFs. Designations for the encoded proteins are also provided. The number of basepairs in the eight intergenic regions is given in parentheses. A minus sign denotes an overlapping region. Calculated codon adaptation indices (CAl; Sharp \& Li, 1987) and the GC content of each gene are indicated below that gene. 


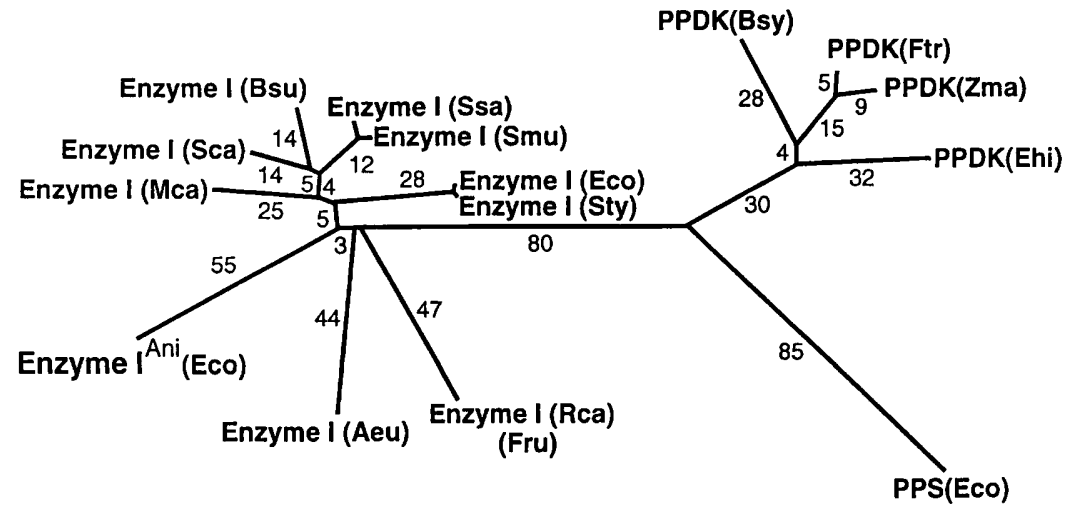

Fig. 2. Phylogenetic tree of the family of proteins that include the bacterial, protozoan and plant pyruvate phosphate dikinases (PPDKs), phosphoenolpyruvate synthase (PPS) of $E$. coli and the Enzyme I proteins and protein domains of the bacterial PTS. Branch length (in arbitrary units) is proportional to phylogenetic distance. Abbreviations used and references to the published protein sequences are as follows: PPS, phosphoenolpyruvate synthase of $E$. coli (Eco) (Niersbach et al., 1992); PPDK, pyruvate phosphate dikinases of Bacteroides symbiosus (Bsy) (Pocalyko et al., 1990), Flaveria trinervia (Ftr) (Rosche \& Westhoff, 1990), Entamoeba histolytica (Ehi) (Bruchhaus \& Tannich, 1993), and Zea mays (Zma) (Matsuoka et al., 1988); Enzyme I, Enzymes I of Alcaligenes eutrophus (Aeu) (Pries et al., 1991), Escherichia coli (Eco) (Saffen et al., 1987; De Reuse \& Danchin, 1988), Rhodobacter capsulatus [Rca; fructose specific (Fru); Wu et al., 1990], Staphylococcus carnosus (Sca) (Kohlbrecher et al., 1991), Streptococcus salivarius (Ssa) (Gagnon et al., 1992), Streptococcus mutans (Smu) (Boyd et al., 1994), and Salmonella typhimurium (Sty) (Byrne et al., 1988; LiCalsi et al., 1991). The Enzyme I protein domain (Enzyme $I^{A n i}$ ) is encoded by the ptsA gene of $E$. coli (Eco) described here. Not presented is the homologous, C-terminal region (110 residues) of the Bacillus stearothermophilus pyruvate kinase (Sakai \& Ohta, 1993).

\section{Table 1. Binary comparisons of the seven transaldolase family (TAF) members}

Values in parentheses below the designations of the proteins refer to the numbers of residues in the intact proteins. The FASTA program using the dipeptide identities mode $(\mathrm{ktup}=2$ ) (Pearson \& Lipman, 1988) was used to assess similarities of the indicated proteins. Values presented in the table which are not in brackets or parentheses represent percentage identities for segments having the numbers of compared residues indicated in parentheses. Comparison scores in standard deviations, using the RDF2 program (Pearson \& Lipman, 1988) and 150 shuffles are given in brackets below the values for percentage identity. Abbreviations and references to the published sequences are as follows. The hypothetical protein in the spoOF region of B. subtilis [ORFU (Bsu); Trach et al., 1988]; the ORF (ORF f220) located downstream of pts $A$ of E. coli [ORF f220 (Eco); Blattner $e t$ al., 1993];

transaldolase of Saccharomyces cerevisiae [Tal1 (Sce); Schaaff et al., 1990]; transaldolase of Kluyveromyces lactis [Tal1 (Kla); Jacoby et al., 1993]; transaldolase of Homo sapiens [Tal (Hsa); Banki et al., 1994]; transaldolase of E. coli [TalB (Eco); Yura et al., 1992]. The partially sequenced transaldolase A of E. coli (G. A. Sprenger, unpublished data cited in SwissProt, accession no. P80218) is abbreviated TalA (Eco).

\begin{tabular}{|c|c|c|c|c|c|c|}
\hline & $\begin{array}{c}\text { ORFU } \\
\text { (Bsu) } \\
(186)\end{array}$ & $\begin{array}{l}\text { Tal1 } \\
\text { (Sce) } \\
(335)\end{array}$ & $\begin{array}{l}\text { 'Tal1 } \\
\text { (Kla) } \\
\text { (334) }\end{array}$ & $\begin{array}{c}\text { Tal } \\
\text { (Hsa) } \\
(336)\end{array}$ & $\begin{array}{c}\text { TalB } \\
(\text { Eco) } \\
(317)\end{array}$ & $\begin{array}{c}\text { TalA } \\
\text { (Eco) } \\
\text { (40; fragment) }\end{array}$ \\
\hline ORFf220 (Eco) & $37(181)$ & $17(216)$ & $36(55)$ & $27(52)$ & $26(58)$ & $20(25)$ \\
\hline$(220)$ & [28] & [4] & [5] & [3] & [4] & {$[2]$} \\
\hline ORFU (Bsu) & & $34(101)$ & $26(133)$ & $31(105)$ & $33(78)$ & $29(21)$ \\
\hline$(186)$ & & [7] & [6] & [11] & [8] & [2] \\
\hline Tal1 (Sce) & & & $76(335)$ & $58(333)$ & $55(317)$ & $53(36)$ \\
\hline$(335)$ & & & [137] & [109] & {$[100]$} & [9] \\
\hline Tal1 (Kla) & & & & $59(332)$ & $57(318)$ & $49(39)$ \\
\hline$(334)$ & & & & [109] & [87] & [9] \\
\hline Tal (Hsa) & & & & & $58(320)$ & $66(35)$ \\
\hline$(336)$ & & & & & [114] & {$[20]$} \\
\hline TalB (Eco) & & & & & & $80(40)$ \\
\hline$(317)$ & & & & & & [22] \\
\hline
\end{tabular}



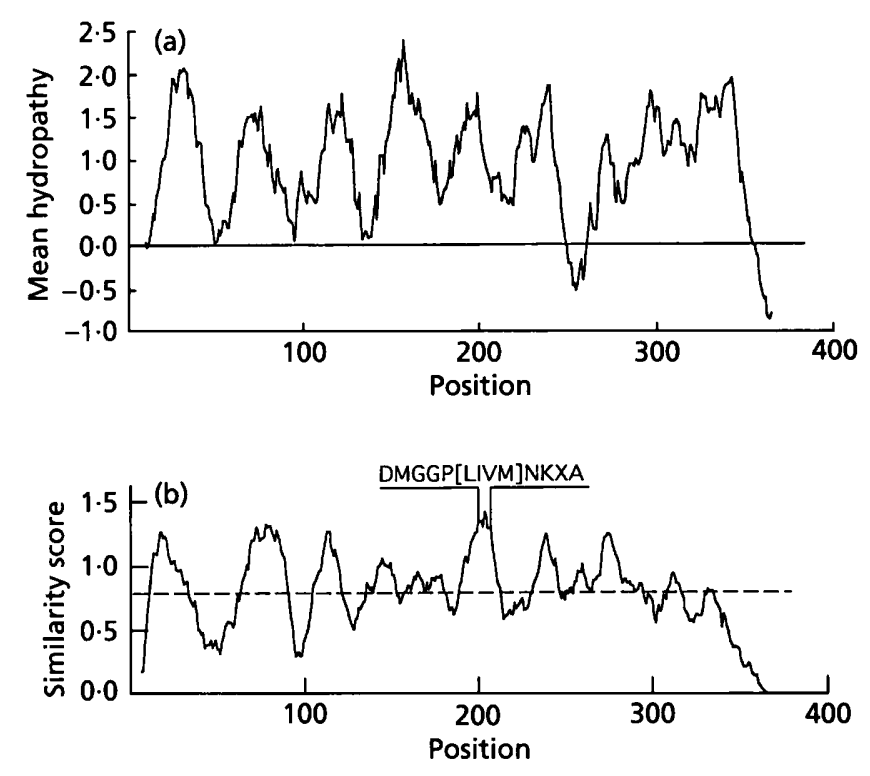

Fig. 3. Mean hydropathy (a) and similarity (b) plots of the fructose IIC-like family (FCF) members. Mean similarity and hydropathy values were calculated as described in Methods. The mean similarity across the entire alignment in (b) is represented by the dashed line. The signature sequence of the FCF proteins and its location are shown above the mean similarity plot in (b). Residues in brackets indicate alternative possibilities at a single position; $X$, any residue.

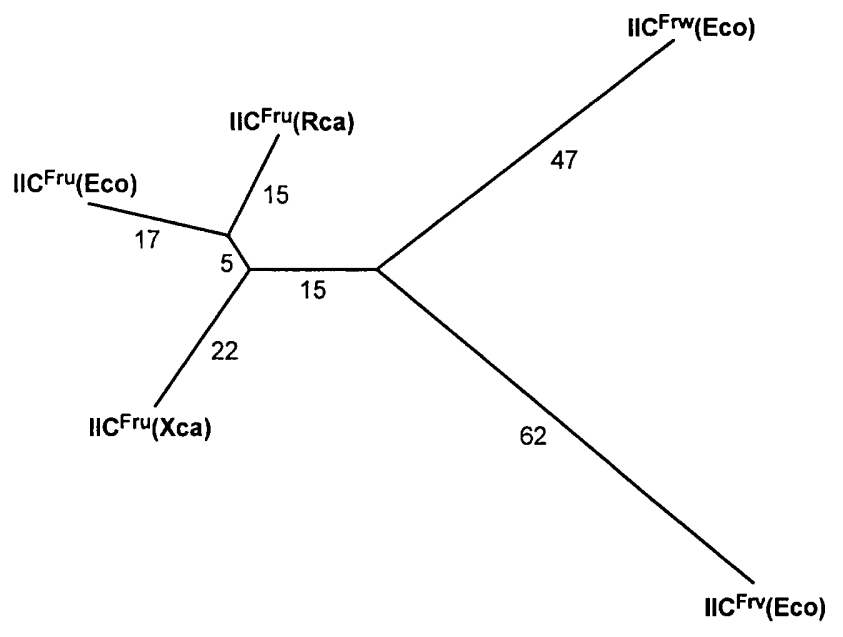

Fig. 4. Evolutionary tree of the fructose IIC-like family (FCF) of proteins or protein domains. Relative phylogenetic distances (in arbitrary units) are provided adjacent to the branches. Abbreviations and references to the published sequences are as follows. Sequenced IIC protein domains of fructose permeases (IICFru) include those from Escherichia coli (Eco; Prior \& Kornberg, 1988), Rhodobacter capsulatus (Rca; Wu \& Saier, 1990) and Xanthomonas campestris (Xca; de Crecy-Lagard et al., 1991). The IIC protein domain of the Frv permease of $E$. coli [IIC Frv(ECo); Plunkett et al., 1993; Reizer et al.., 1994a] and the IIC protein of the Frw permease of $E$. coli [IIC $C^{\mathrm{Frw}}(\mathrm{ECO})$; Blattner et al., 1993] are also represented. For a multiple alignment of all fructose-specific and fructose IIC-like proteins or protein domains except IIC ${ }^{\mathrm{Frw}}$ (ECo), see Fig. 3 in Reizer et al. (1994a).
All of these ORFs were analysed for sequence similarity to proteins in the current databases, and homologous proteins identified are discussed below for the individual proteins. When appropriate, multiple alignments, mean similarity plots, binary comparison tables and phylogenetic trees were derived. Data not presented in this paper will be supplied upon request to M. H. Saier, Jr.

\section{Enzyme IAni}

The amino acid sequence of the $\mathrm{N}$-terminal 560 residues of Enzyme I $^{\mathrm{Ani}}$ (EI $^{\mathrm{Ani}}$ ) exhibits striking sequence similarity to all of the Enzymes I of the PTS throughout most of its length (503-556-residue overlap). It was 34-37\% identical to all previously sequenced Enzymes I except that from Alcaligenes eutropbus, to which it was $32 \%$ identical. Comparison scores, determined with the RDF2 program (Pearson \& Lipman, 1988) gave values ranging between 79 and 121 sD, thereby establishing homology. A multiple alignment of 10 distinct Enzymes I, the E. coli phosphoenolpyruvate synthase and the four sequenced pyruvate phosphate dikinases (from bacteria, protozoa and plants) revealed that almost all fully conserved residues in the Enzyme I family, and all established catalytic residues (the TSH motif that includes the phosphorylated histidine and the C-terminal CG residue pair that includes the conserved cysteine, both believed to be of catalytic significance), are also conserved in $\mathrm{EI}^{\mathrm{Ani}}$ (see Reizer et al., 1993, for a multiple alignment of 11 members of this family). Comparison scores obtained with phosphoenolpyruvate synthase of E. coli $(19 \mathrm{sD})$ and various pyruvate phosphate dikinases (8-15 SD) were also of sufficient magnitude to establish homology. Phylogenetic tree construction surprisingly revealed that $\mathrm{EI}^{\mathrm{Ani}}$ is more similar to the Enzymes I of Gram-positive bacteria than to those of enteric bacteria (Fig. 2). It was most distant from Enzymes I of $A$. eutrophus and Rhodobacter capsulatus. The IIA domain (147 residues) at the Cterminus of $\mathrm{EI}^{\mathrm{Ani}}$ (here designated IIA $^{\mathrm{Frw}}$ ) showed greatest sequence similarity to IIA ${ }^{\text {Frv }}$ of E. coli $(28 \%$ identity in an amino acid overlap of 144 residues; 20 SD).

\section{Transaldolase homologue (TalC)}

Adjacent to the $p t s A$ gene, and downstream from it, is an ORF, orf f220, which we have designated talC (Fig. 1). The encoded protein exhibits $37 \%$ identity in 181 residues $(28 \mathrm{sD})$ to a protein encoded by an ORF in Bacillus subtilis (orf $U$ ) that maps adjacent to fructose-1,6-bisphosphate aldolase (Trach et al., 1988). As revealed by the statistical analyses recorded in Table 1, OrfU is homologous to transaldolases of bacteria, yeast and man. TalC exhibits only very weak sequence similarity with the latter proteins, but based on the superfamily principle (Doolittle, 1986) all proteins included in Table 1 are members of a single family, here designated the transaldolase family (TAF). A signature sequence was derived for this family and was shown to be specific for the seven known members of the family. The signature sequence is: TTNPS[LIVM $]_{2}[$ LIVMA] (residues in brackets represent alternative residues at a particular position). 
Table 2. Binary statistical comparisons of members of the fructose IIB-like protein or protein domain family (FBF)

The abbreviations used and references to the published sequences are as follows. The conserved, putative catalytic IIB protein domains $\left(\right.$ IIB $^{\text {Fru }}$ ) of the fructose-specific Enzymes II of E. coli (Eco) (Prior \& Kornberg, 1988), of Rbodobacter capsulatus (Rca) (Wu \& Saier, 1990) and of Xanthomonas campestris (Xca) (de Crecy-Lagard et al., 1991). The poorly conserved, presumed noncatalytic protein domains (IIB ${ }^{\mathrm{Fru}}$ ) of the fructose-specific Enzymes II of E. coli (Eco) (Prior \& Kornberg, 1988), of R. capsulatus (Rca) (Wu \& Saier, 1990) and of $X$. campestris (Xca) (de Crecy-Lagard et al., 1991). The single IIB protein domain of the Frv PTS of E. coli [IIB ${ }^{\text {Frv }}$ (Eco); Plunkett et al., 1993; Reizer et al., 1994a], a partially sequenced ORF of Mycoplasma genitalium [ORF107(Mge); Peterson et al., 1993], and the IIB proteins of the Frw PTS [IIB ${ }^{\text {Frw }}(\mathrm{Eco})$ and IIB ${ }^{\text {Frw' }}$ (Eco) of E. coli; Blattner et al., 1993]. Values in parentheses below the designations of the proteins refer to the numbers of residues in the intact proteins or protein domains. The FASTA program, using the dipeptide identities mode (ktup = 2) (Pearson \& Lipman, 1988), was used to assess the similarities of the indicated proteins. Values presented in the table which are not in brackets or parentheses represent percentage identities for segments having the numbers of compared residues indicated in parentheses. Comparison scores in standard deviations, using the RDF2 program (Pearson \& Lipman, 1988) and 150 shuffles, are given in brackets below the values for percentage identities.

\begin{tabular}{|c|c|c|c|c|c|c|c|c|c|}
\hline & $\begin{array}{c}\mathrm{IIB}^{\mathrm{Fru}} \\
\text { (Rca) } \\
(99)\end{array}$ & $\begin{array}{c}\mathrm{IIB}^{\mathrm{Fru}} \\
(\mathrm{Xca}) \\
(99)\end{array}$ & $\begin{array}{c}\mathrm{IIB}^{\mathrm{Frv}} \\
(\mathrm{Eco}) \\
(92)\end{array}$ & $\begin{array}{c}\text { ORF107 } \\
\text { (Mge) } \\
(107)\end{array}$ & $\begin{array}{l}\mathrm{IIB}^{\mathrm{Frw}} \\
(\text { Eco) } \\
(106)\end{array}$ & $\begin{array}{c}\mathrm{IIB}^{\mathrm{F} F \mathrm{w}^{\prime}} \\
(\mathrm{Ecco}) \\
(113)\end{array}$ & $\begin{array}{c}\mathrm{IIB}^{\mathrm{Fru}} \\
\text { (Rca) } \\
(90)\end{array}$ & $\begin{array}{c}\mathrm{IIB}^{\mathrm{Pru}} \\
\text { (Xca) } \\
\text { (90) }\end{array}$ & $\begin{array}{c}\mathrm{IIB}^{\mathrm{Fru}}{ }^{\prime} \\
(\mathrm{Eco}) \\
(84)\end{array}$ \\
\hline IIB $^{\text {Fru }}($ Eco $)$ & $57(98)$ & $55(98)$ & $48(85)$ & $51(85)$ & $51(95)$ & $37(95)$ & $43(88)$ & $28(83)$ & $21(28)$ \\
\hline$(100)$ & [31] & [46] & {$[23]$} & {$[24]$} & {$[28]$} & [23] & [25] & {$[10]$} & [1] \\
\hline $\mathrm{IIB}^{\text {Fru }}(\mathrm{Rca})$ & & $54(97)$ & $52(86)$ & $48(85)$ & $44(93)$ & $33(94)$ & $47(85)$ & $24(86)$ & $26(43)$ \\
\hline (99) & & [35] & [30] & [20] & {$[26]$} & {$[27]$} & {$[22]$} & [13] & [3] \\
\hline $\mathrm{IIB}^{\text {Fru }}(\mathrm{Xca})$ & & & $56(80)$ & $49(86)$ & $42(95)$ & $42(71)$ & $41(87)$ & $27(85)$ & $21(38)$ \\
\hline (99) & & & [25] & [25] & {$[28]$} & [16] & [21] & {$[10]$} & [2] \\
\hline $\mathrm{IIB}^{\mathrm{Frv}}$ (Eco) & & & & $46(84)$ & $52(85)$ & $46(70)$ & $45(85)$ & $22(83)$ & $29(28)$ \\
\hline (92) & & & & [24] & [30] & [19] & {$[20]$} & [6] & [3] \\
\hline ORF107 (Mge) & & & & & $49(86)$ & $44(71)$ & $38(85)$ & $26(69)$ & $67(3)$ \\
\hline (107) & & & & & {$[24]$} & [17] & {$[16]$} & [5] & {$[-1]$} \\
\hline $\mathrm{IIB}^{\mathrm{Frw}}$ (Eco) & & & & & & $43(103)$ & $41(91)$ & $26(88)$ & $26(50)$ \\
\hline (106) & & & & & & {$[28]$} & {$[18]$} & [9] & [3] \\
\hline $\mathrm{IIB}^{\mathrm{Frw}{ }^{\prime}}$ (Eco) & & & & & & & $38(74)$ & $37(27)$ & $15(34)$ \\
\hline (113) & & & & & & & {$[13]$} & [3] & [2] \\
\hline $\operatorname{IIB}^{\text {Fru' }}(\mathrm{Rca})$ & & & & & & & & $31(88)$ & $24(33)$ \\
\hline & & & & & & & & {$[10]$} & [1] \\
\hline $\mathrm{IIB}^{\mathrm{Fru}}(\mathrm{Xca})$ & & & & & & & & & $20(20)$ \\
\hline$(90)$ & & & & & & & & & {$[0.1]$} \\
\hline
\end{tabular}

\section{Glycerol dehydrogenase (GIdA)}

Downstream from and adjacent to $\mathrm{tal} C$ is the gld $A$ gene encoding the E. coli glycerol dehydrogenase (Truniger \& Boos, 1994). The encoded protein exhibits $50 \%$ identity in a 362-residue overlap to the glycerol dehydrogenase of Bacillus stearothermophilus (comparison score of $105 \mathrm{sD}$ ) (Mallinder $e t$ al., 1992). It also proved to be homologous to propanediol oxidoreductase (lactaldehyde reductase; FucO) of E. coli (21\% identity in a 274-residue overlap, comparison score of 11 sD (Chen et al., 1989; Lu \& Lin, 1989). Lactaldehyde reductase proved to be homologous to many oxidoreductases including numerous sequenced alcohol dehydrogenases (data not presented).

\section{ORF 0109}

The putative protein encoded by orf 0109 (ORF o109) possesses an $\mathrm{N}$-terminal 70-residue segment that is rich in serine $(30 \%)$. However, the encoded sequence does not exhibit significant similarity to those of other proteins in the current databases, and it lacks a demonstrable helix-turn-helix motif.

\section{IIC Fww (FrwC)}

ORF o359 (herein designated IIC $^{\text {Frw }}$ or FrwC) is a hydrophobic protein of 359 residues. This protein proved to be homologous to the IIC domains of all sequenced Enzymes II specific for fructose as well as to the IIC domain of the recently described fructose-like PTS protein, FrvC (comparison scores ranging from 29 to $49 \mathrm{sD}$ ). We refer to this family of proteins as the fructosespecific or fructose-like IIC family (FCF).

The multiple alignment of these five protein sequences revealed many fully conserved residues, including the glutamate that is conserved in most Enzymes II (Wu \& Saier, 1990) and is essential for function in the mannitol Enzyme IIC (Jacobson \& Saraceni-Richards, 1993; for the multiple alignment of all fructose-specific IIC domains and fructose IIC-like domains except IIC ${ }^{\text {Frw }}$ see Fig. 3 in 


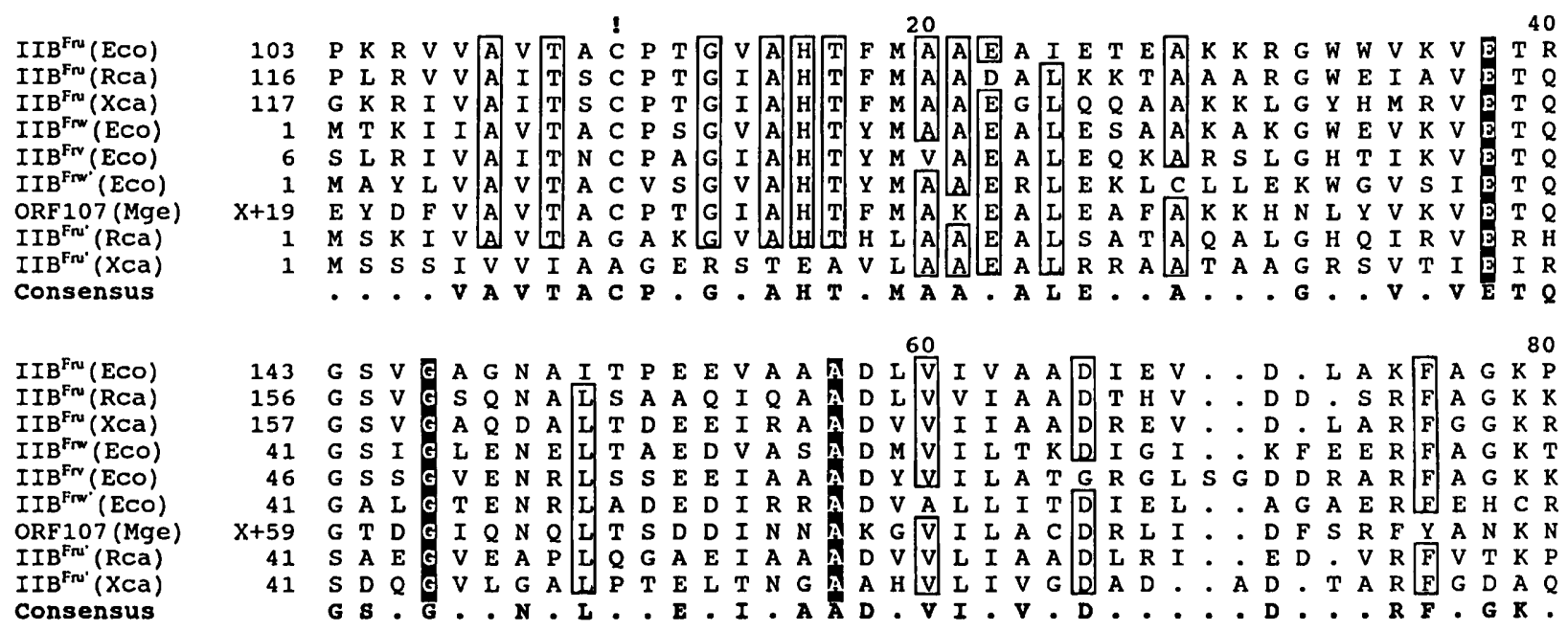

$I I I B^{\mathrm{Fru}}$ (ECO) $\quad 180$ M Y R T S T G L A L K K T A Q E

$I_{I B}{ }^{F}$ (RCa) $\quad 193$ V Y K T S V G A A V K G A A K V

$I I B^{\mathrm{Fru}}$ (XCa) $\quad 194$ L F K S G T K P A I N D G P A L

$I_{I B^{\text {Frw }}(E C O)} \quad 79 \quad I$ V R V N I S D A V K R A D A I

$I I B^{\mathrm{FN}}$ (ECO) $\quad 86$ V Y E I A I S Q A L K N I D Q I

$\operatorname{IIB}^{\mathrm{FrW}}(\mathrm{ECO}) \quad 79 \quad \mathrm{Y}$ V Q C S I Y A F L R E P Q R V

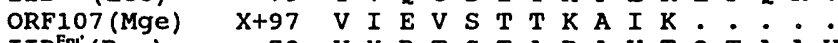

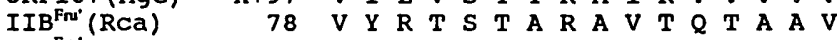

$I B^{\mathrm{Fru}}$ (XCa) $\quad 78$ L L H L S L G A V L D D P A A V

Consensus

-. . S . - A K . . .

Fig. 5. Multiple alignment of the fructose IIB-like family (FBF). Fully conserved residues are highlighted (black background) whereas residues conserved in at least eight members of the FBF are boxed. The exclamation mark denotes the presumed active-site cysteyl residue (site of phosphorylation) in the catalytic IIB proteins or domains. Residues common to at least five of the nine sequenced proteins or domains are presented in the consensus sequence at the bottom. Numbers to the left of the sequences shown provide residue numbers in the individual proteins. Numbers above the aligned sequences refer to the alignment positions and not to the residue numbers in any one of the aligned proteins. For abbreviations and references to the published sequences, see Table 2 . The noncatalytic IIB ${ }^{\text {Fru }}$ of $E$. coli is not included in the multiple alignment due to its extensive divergence (see Table 2).

Reizer et al., 1994a). Several conserved hydrophilic residues in members of this family may be important for catalysis, while the strongly conserved hydrophobic regions may correspond to transmembrane $\alpha$-helical spanners, similar to those of other PTS permeases (Sugiyama et al., 1991; Buhr \& Erni, 1993).

The mean hydropathy and similarity plots for these five proteins are presented in Fig. 3. It can be seen that in general, the putative hydrophobic spanners are better conserved than are the hydrophilic loops. The most conserved region was used to construct a signature sequence for this family of proteins (see Fig. 3), and this sequence, DMGGP[LIVM]NKXA, proved to be specific to the five members of the family when the SwissProt database (version 28) was screened. Six to nine transmembrane spanners were predicted on the basis of the method of Kyte \& Doolittle (1982) for the various members of the family.

The phylogenetic tree for these proteins is shown in Fig. 4. IIC ${ }^{\text {Frw }}$ (Eco) is apparently distant from all other members, whereas the three biochemically characterized fructose IIC domains are closely related to each other.
This fact suggests that $\mathrm{IIC}^{\mathrm{Frv}}$ and $\mathrm{IIC}^{\mathrm{Frw}}$ may possess a function dissimilar from those of the biochemically wellcharacterized fructose-specific Enzymes IIC.

\section{$\mathrm{IIB}^{\mathrm{Fw}}$ and $\| \mathrm{B}^{\mathrm{Fw}}$ (FrwB and FrwD)}

The frw operon contains two ORFs that are homologous to each other as well as to the IIB ${ }^{\mathrm{Fru}}$ domains of fructosespecific Enzymes II. Correlating with the fact that all biochemically characterized Enzymes II specific for fructose contain two adjacent IIB domains, the frw operon contains two IIB $^{\mathrm{Fru}}$-like encoding genes. The frw operon is the first operon to contain fructose IIC and duplicated IIB-like domains as separate polypeptide chains encoded by distinct genes.

The binary statistical comparison scores for the ten members of the IIB $^{\mathrm{Fru}}$ family (FBF) are presented in Table 2. These scores are sufficient in magnitude to establish homology of $\mathrm{IIB}^{\mathrm{Frw}}$ and $\mathrm{IIB}^{\mathrm{Frw}}$ to all other members of the family except the N-terminal IIB domain $\left(\right.$ IIB $^{\text {Fru' }}$ ) of the functionally characterized fructose-specific Enzyme II of E. coli. The data in Table 2 reveal that IIB $^{\text {rrw }}$ exhibits greater sequence similarity to other 


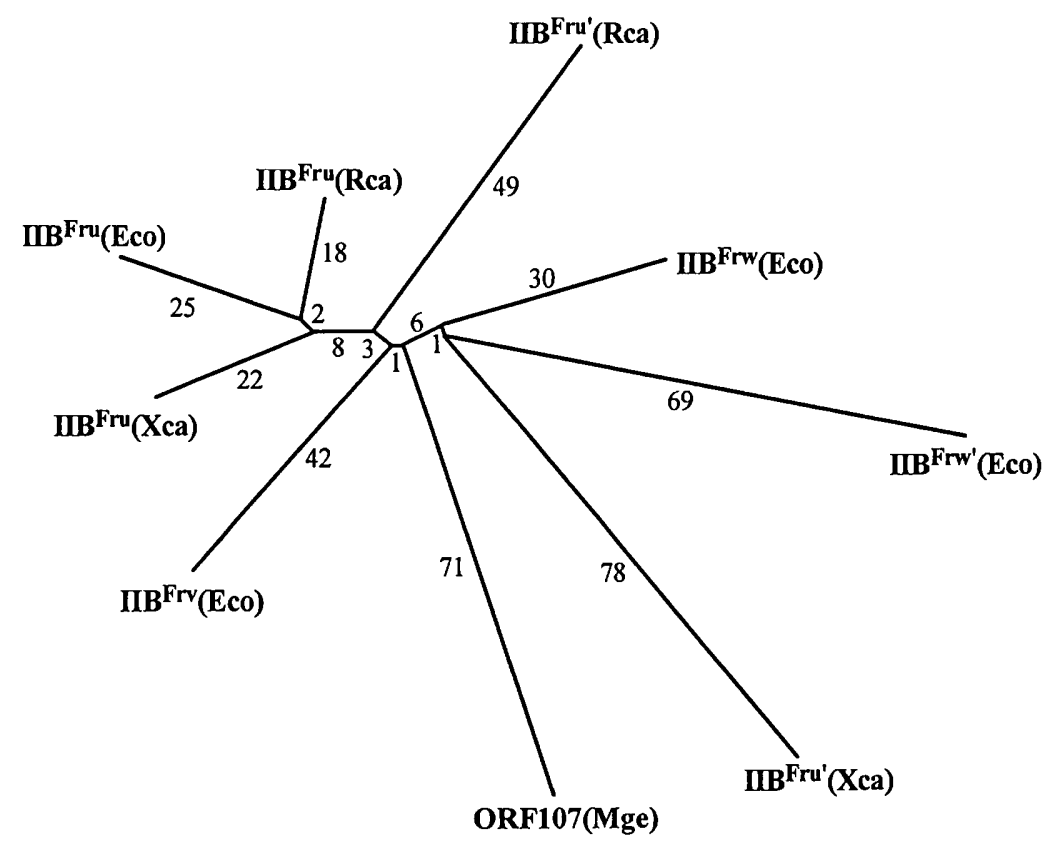

Fig. 6. Evolutionary tree of members of the fructose IIB-like family (FBF). Relative branch lengths, proportional to phylogenetic distance, are shown adjacent to the branches. Abbreviations are as indicated in the legend to Table 2. Construction of the tree was as described by Reizer \& Reizer (1994) using the progressive alignment method of Feng \& Doolittle (1990).

members of the family than does $\mathrm{IIB}^{\mathrm{Frw}}$ (hence the designation of the latter protein as $\mathrm{IIB}^{\mathrm{Frw}}$ ). It is noteworthy that both of the Frw IIB proteins are much more similar to the catalytic IIB domains of the fructose Enzymes II than to the noncatalytic, N-terminal IIB' domains of the same Enzymes II.

The multiple alignment of all but one of these protein sequences is presented in Fig. 5. The noncatalytic Nterminal IIB ${ }^{\mathrm{Fru}}$ sequence of the E. coli fructose Enzyme II was omitted due to its extensive divergence (Wu et al., 1990; see similarity scores in Table 2). Only three residues are conserved in all members of the family (E, G and A at positions 38, 44 and 57, respectively). Several residues are conserved in all but one member of the family (boxed residues), and both proteins, FrwB and FrwD, contain the residues proposed to be essential for the phosphoryl transfer reactions involved in sugar uptake. These include the cysteine at position 10 and the histidine at position 16 of the multiple alignment. As is apparent from the alignment, the $\mathrm{N}$-terminal regions of these proteins are more strongly conserved than the C-terminal regions.

The phylogenetic tree of the fructose IIB-like family (FBF) is shown in Fig. 6. All catalytically active IIB Fru domains cluster tightly together on this tree. The IIB ${ }^{\mathrm{Frv}}$, the $\operatorname{IIB}^{\mathrm{Frw}}$ and the $R$. capsulatus $\mathrm{IIB}^{\mathrm{Fru}}$ are about equidistant from this cluster while the IIB ${ }^{\mathrm{Frw}^{\prime}}$ domain is much more distant. This result suggests that the frw $B$ gene product may provide the primary function of the Frw Enzyme II complex.

\section{A pyruvate formate-lyase homologue (PfID)}

Downstream of the frw $B$ gene is orf $0765(\not A D)$ encoding a protein that is homologous throughout most of its length to pyruvate formate-lyase (PfB) of E. coli (759 residues). The two proteins exhibit $21 \%$ identity in a 518 residue overlap with a binary comparison score of $44 \mathrm{sD}$. Other homologues were also identified (Table 3). The glycyl residue that is converted to a free radical by the Pflactivating enzyme (Wagner et al., 1992) is conserved in PfD. Surrounding this glycyl residue at the $\mathrm{C}$-terminal region of these proteins is a sequence that is fully conserved between these two proteins and is largely conserved in the other homologues listed in Table 3. This sequence is: Y[AP][NQ]L[TV][IV]RV[SA]GY[SA][A$\mathrm{V}] \mathrm{XF}$ (amino acid at a position in which the residue is not specified is denoted by X). Although an anaerobic E. coli ribonucleotide reductase, $\mathrm{NrdD}$, exhibits similar mechanisms of action and activation (Sun et al., 1993), it is not demonstrably homologous to any of the members of the Pfl family listed in Table 3.

\section{A pyruvate-formate-lyase-activating enzyme homologue (PflC)}

Downstream of $p A D$ is orf $0315(p f C)$, a gene that encodes a homologue of the known pyruvate-formate-lyaseactivating enzyme, PflA of E. coli, 245 residues in length. These two proteins exhibit $27 \%$ identity in a 197 amino acid overlap with a comparison score of $27 \mathrm{sD}$. The E. coli Pfl-activating enzyme is also homologous to a phage T4 ORF (ORF156) (35\% identity in a 71-residue overlap; $13 \mathrm{SD})$. The results reported in this and the previous section suggest that this gene cluster encodes an enzyme that exhibits mechanisms of activation and action like those of the E. coli PflB. In spite of the similarities noted above between PfD and ORF o315 with PfB and PfA, respectively, the low percentage identities observed between these pairs of homologous proteins do not allow the unequivocal conclusion that the former enzyme is a pyruvate formate-lyase. 
Table 3. Binary comparisons of the six pyruvate formate lyase (PFL) family members

Values in parentheses below the designation of a protein refer to the number of residues in that protein. The FASTA program using the dipeptide identities mode $(\mathrm{ktup}=2$ ) (Pearson \& Lipman, 1988) was used to assess similarities of the indicated proteins. Values presented in the table which are not in brackets or parentheses represent percentage identities for segments having the numbers of compared residues indicated in parentheses. Comparison scores in standard deviations using the RDF2 program (Pearson \& Lipman, 1988) and 150 shuffles are given in brackets below the values for percentage identity. Abbreviations and references to the published sequences are as follows. The ORF (ORF o765) in the Frw PTS region of E. coli [ORF o765 (Eco); Blattner et al., 1993], pyruvate formate lyase of E. coli [PfB (Eco); Rodel et al., 1988], the partially sequenced pyruvate formate lyase of Chlamydomonas reinhardtii [PA (Cre); submitted to EMBL (accession no. S24997) by F. Dumont], and the hypothetical proteins of Serratia liquefaciens [ORF106 (Sli); Givskov et al., 1988], of E. coli [ORF127 (Eco); Varshney et al., 1988], and of the phage T4 [ORF120 (T4); Valerie et al., 1986].

\begin{tabular}{|lccccc|}
\hline & $\begin{array}{c}\text { PfB (Eco) } \\
\text { (759) }\end{array}$ & $\begin{array}{c}\text { Pf (Cre) } \\
\text { (195; fragment) }\end{array}$ & $\begin{array}{c}\text { ORF106 (Sli) } \\
\text { (106; fragment) }\end{array}$ & $\begin{array}{c}\text { ORF127 (Eco) } \\
\mathbf{( 1 2 7 )}\end{array}$ & $\begin{array}{c}\text { ORF120 (T4) } \\
\mathbf{( 1 2 0 )}\end{array}$ \\
\hline ORFo765 (Eco) & $21(518)$ & $35(192)$ & $42(52)$ & $42(52)$ & $42(52)$ \\
(765) & {$[44]$} & {$[28]$} & {$[12]$} & {$[13]$} & {$[13]$} \\
PfB (Eco) & & $62(200)$ & $73(66)$ & $77(64)$ & $73(66)$ \\
(759) & {$[75]$} & {$[23]$} & {$[21]$} & {$[23]$} \\
Pfl (Cre) & & & $68(60)$ & $68(60)$ & $67(60)$ \\
(195; fragment) & & & {$[28]$} & {$[28]$} & {$[27]$} \\
ORF106 (Sli) & & & & $83(107)$ & $77(90)$ \\
(106; fragment) & & & & {$[42]$} & {$[39]$} \\
ORF127 (Eco) & & & & & $72(100)$ \\
(127) & & & & & {$[40]$} \\
\hline
\end{tabular}

\section{DISCUSSION}

In 1987 we demonstrated that Salmonella typhimurium, deleted of the $p t s$ operon which encodes Enzyme I and $\mathrm{HPr}$, could be mutated to allow expression of a novel and presumably cryptic Enzyme I. This novel enzyme could readily substitute for the deleted Enzyme I (Chin $e t$ al., 1987). A mutation which allowed expression of the encoding gene was mapped by transduction and shown to be localized between $c r r$ and $c y s M$ at $49.5 \mathrm{~min}$ on the Salmonella chromosome. This putative gene was designated $p t s J$.

We have recently sequenced a $4.5 \mathrm{kbp}$ region of the Salmonella chromosome between $c y s M$ and $c r r$ and have identified an ORF which encodes a protein that possesses an identifiable $\mathrm{N}$-terminal helix-turn-helix motif homologous to those of members of the B. subtilis gluconate repressor (GntR) family (Titgemeyer et al., 1994; Buck \& Guest, 1989; Reizer et al., 1991a). No ORF encoding an Enzyme I-like protein was found in this region. The structural gene for the cryptic Enzyme I therefore had to map elsewhere on the chromosome.

Geerse (1989) confirmed the observation of Chin et al. (1987) that a mutation in S. typhimurium near the crr gene allowed expression of a cryptic Enzyme I. Similarly, Kornberg (1990) reported that mutations in the genetic background of an E. coli strain that lacks the $p t s H$ and $p t s I$ genes restore fructose utilization. In the former work, mutation in addition to that in ptsJ was thought to be requisite for this expression, and this gene was claimed to cotransduce with the fru operon (Geerse, 1989). Extensive sequencing around the fru operon (G. M. Church and others, data submitted to GenBank, accession number U00007) has not yet revealed the presence of an Enzyme I-encoding gene in this region.

By contrast, genome sequencing efforts in the 89.2-92.8 region (Blattner et al., 1993) revealed an ORF encoding an

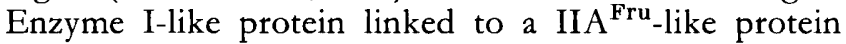
domain at its C-terminus. Analysis of other ORFs in the same gene cluster revealed that other PTS-proteinencoding genes, two encoding IIB $^{\mathrm{Fru}}$-like proteins, and one encoding a IIC ${ }^{\mathrm{Fru}}$-like protein, are present. This gene cluster therefore encodes all of the constituents of a fructose-specific PTS (Enzyme I, IIA ${ }^{\text {Frw }}$, IIB ${ }^{\text {Frw }}$, IIB ${ }^{\text {Frw }}$ and $\mathrm{IIC}^{\mathrm{H} r \mathrm{w}}$ ), except for an HPr-like protein. In this regard it is interesting to note that the $f r u$ operon of enteric bacteria encodes a protein (DTP) in which an HPr-like domain is fused to a IIA ${ }^{\mathrm{Fru}}$-like domain (Geerse et al., 1989; Wu et al., 1990; Reizer et al., 1994b). This HPr-like domain (termed FPr or fructose-inducible $\mathrm{HPr}$ ) can fully replace $\mathrm{HPr}$ in sugar phosphorylation (Sutrina et al., 1988). Further, many bacteria possess only a fructosespecific PTS (see Romano \& Saier, 1992, for a summary of the data) and in some of these, the Enzyme I-like domain (C-terminus) is linked to an HPr domain (middle) and a

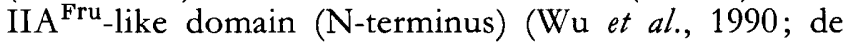
Crecy-Lagard et al., 1991). It has been postulated that the fructose PTS was the primordial system (Saier, 1977; Saier et al., 1985).

In E. coli and other bacteria, several gene products homologous to proteins of the fructose PTS have now 
been found. The $f r u$ operon of this organism encodes (a) DTP, the three-domain diphosphoryl transfer protein referred to above that includes the IIA $^{\mathrm{Fru}}$ and $\mathrm{FPr}$ domains, (b) a fructose-1-phosphate kinase, and (c) a fructose-specific Enzyme II having tandemly duplicated IIB domains as well as a IIC domain, all in a single polypeptide chain. Rhodobacter capsulatus and Xanthomonas campestris possess similar systems but with Enzyme I, $\mathrm{HPr}$ and IIA ${ }^{\mathrm{Fru}}$ linked within a single polypeptide chain (Wu et al., 1990; de Crecy-Lagard et al., 1991). The recently described $f r v$ operon has a gene encoding a IIA ${ }^{\mathrm{Fru}}$-like protein as well as a gene encoding a fused $\mathrm{IIB}^{\mathrm{Fru}}{ }_{-} \mathrm{IIC}^{\mathrm{Fru}}$ like protein. This last-mentioned protein has only one IIB domain (see Fig. 7 in Reizer $e t$ al., 1994a, for a schematic depiction of these proteins). Finally, the present analyses have revealed a third fru-like gene cluster with four distinct PTS-protein-encoding genes, one for the Enzyme

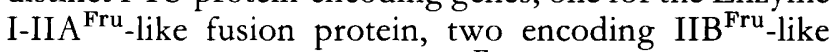
proteins, and one encoding a IIC ${ }^{\mathrm{Fru}}$-like protein. In terms of its PTS-protein-domain-encoding content, this frw gene cluster therefore resembles the fru operon rather than the $f r v$ operon.

The diversity of the fructose-like PTS proteins noted above evidently resulted from domain shuffling and splicing which must have occurred during the evolution of these and other PTS proteins (Saier \& Reizer, 1992). Thus, in various systems, IIA, IIB and IIC may be linked together in a single polypeptide chain or they may be found as two or three autonomous polypeptide chains encoded by distinct genes. Further, the various domains can be linked to each other in different but non-random orders (Saier \& Reizer, 1992, 1994b).

The Enzyme I-IIA ${ }^{\text {Fru }}$ protein reported here is unique to currently recognized PTS proteins in its domain content and order. Interestingly, previously sequenced IIA domains were always found in Enzyme II-containing polypeptide chains as C-terminal domains (Saier \& Reizer, 1992, 1994b). By contrast, all previously known general energy-coupling PTS proteins bearing a IIA domain exhibit the IIA domain at their N-termini. Enzyme I $^{\text {Ani }}$ is therefore the first general energy-coupling protein of the PTS with a C-terminal IIA domain.

Other enzymes encoded within the frw gene cluster include a glycerol dehydrogenase, a transaldolase homologue, a pyruvate formate-lyase (Pfl) homologue and a Pfl-activating enzyme homologue. The well-characterized PflA is known to function only under anaerobic conditions (Iuchi \& Lin, 1993; Sawers \& Suppmann, 1992). Further, several bacteria induce synthesis of PTS proteins only under anaerobic conditions (Pelliccione et al., 1979; S. Klinke \& M. H. Saier, Jr, unpublished results). It would therefore be reasonable to propose that proteins encoded in the $f r w$ gene cluster function primarily in anaerobic carbon metabolism.

The functions of the proteins encoded within the frw gene cluster are at present unknown. Will the included PTS proteins prove to have significance with respect to sugar uptake, chemotaxis, or regulation? Alternatively, will they prove to be cryptic genes with no identifiable function (Hall et al., 1983; Parker \& Hall, 1990)? Is Enzyme I ${ }^{\text {Ani }}$ the Enzyme I expressed in pts $J$ mutants of $S$. typhimurium (Chin et al., 1987)? Both genetic and biochemical approaches are currently under way to answer these important questions.

\section{ACKNOWLEDGEMENTS}

We are grateful to Mary Beth Hiller for invaluable assistance provided in the preparation of this manuscript. This work was supported by US Public Health Service grants 5RO1 AI 21702 and 2RO1AI 14176 from the National Institute of Allergy and Infectious Diseases.

\section{REFERENCES}

Banki, K., Halladay, D. \& Perl, A. (1994). Cloning and expression of the human gene for transaldolase. A novel highly repetitive element constitutes an integral part of the coding sequence. J Biol Chem 269, 2847-2851.

Blattner, F. R., Burland, V., Plunkett, G., III, Sofia, H. J. \& Daniels, D. L. (1993). Analysis of the Escherichia coli genome. 4. DNA sequence of the region from 89.2 to 92.8 minutes. Nucleic Acids Res 21, 5408-5417.

Boyd, D. A., Cvitkovitch, D. G. \& Hamilton, I. R. (1994). Sequence and expression of the genes for $\mathrm{HPr}(p t s H)$ and Enzyme I $(p t s I)$ of the phosphoenolpyruvate-dependent phosphotransferase transport system from Streptococcus mutans. Infect Immun 62, 1156-1165.

Bruchhaus, I. \& Tannich, E. (1993). Primary structure of the pyruvate phosphate dikinase in Entamoeba histolytica. Mol Biochem Parasitol 62, 153-156.

Buck, D. \& Guest, J. R. (1989). Overexpression and site-directed mutagenesis of the succinyl-CoA synthetase of Eschericbia coli and nucleotide sequence of a gene ( $\mathrm{g} 30$ ) that is adjacent to the suc operon. Biochem J 260, 737-747.

Buhr, A. \& Erni, B. (1993). Membrane topology of the glucose transporter of Escherichia coli. J Biol Chem 268, 11599-11603.

Byrne, C. R., Monroe, R. S., Ward, K. A. \& Kredich, N. M. (1988). DNA sequences of the $c y s K$ regions of Salmonella typhimurium and Escherichia coli and linkage of the cysK regions to ptsH. J Bacteriol 170, 3150-3157.

Chen, Y. M., Lu, Z. \& Lin, E. C. (1989). Constitutive activation of the fuc $A O$ operon and silencing of the divergently transcribed fucPlK operon by an IS5 element in Escherichia coli mutants selected for growth on L-1,2-propanediol. J Bacteriol 171, 6097-6105.

Chin, A. M., Sutrina, S., Feldheim, D. A. \& Saier, M. H., Jr (1987). Genetic expression of Enzyme I activity of the phosphoenolpyruvate: sugar phosphotransferase system in $p t s H I$ deletion strains of Salmonella typhimurium. J Bacteriol 169, 894-896.

de Crecy-Lagard, V., Bouvet, O. M., Lejeune, P. \& Danchin, A. (1991). Fructose catabolism in Xanthomonas campestris pv. campestris. Sequence of the PTS operon, characterization of the fructosespecific enzymes. J Biol Chem 266, 18154-18161.

De Reuse, H. \& Danchin, A. (1988). The $p t s H, p t s I$, and $c r r$ genes of the Escherichia coli phosphoenolpyruvate-dependent phosphotransferase system: a complex operon with several modes of transcription. J Bacteriol 170, 3827-3837.

Devereux, J., Haeberli, P. \& Smithies, N. O. (1984). A comprehensive set of sequence analyses for the VAX. Nucleic Acids Res 12, 387-395.

Doolittle, R. F. (1986). Of Urfs and Orfs: a Primer on How to Analyze 
Derived Amino Acid Sequences. Mill Valley, CA: University Science Books.

Feng, D.-F. \& Doolittle, R. F. (1990). Progressive alignment and phylogenetic tree construction of protein sequences. Methods Enzymol 183, 375-387.

Gagnon, G., Vadeboncoeur, C., Levesque, R. C. \& Frenette, M. (1992). Cloning, sequencing and expression in Eschericbia coli of the ptsI gene encoding the Enzyme I of the phosphoenolpyruvate: sugar phosphotransferase system from Streptococcus salivarius. Gene 121, 71-88.

Geerse, R. H. (1989). The phosphoenolpyruvate : fructose phosphotransferase system in Salmonella typhimurium and Escherichia coli. $\mathrm{PhD}$ thesis, E. C. Slater Institute for Biochemical Research, University of Amsterdam.

Geerse, R. H., Izzo, F. \& Postma, P. W. (1989). The PEP: fructose phosphotransferase system in Salmonella typhimurium: FPr combines Enzyme III ${ }^{\text {Fru }}$ and pseudo-HPr activities. Mol \& Gen Genet 216, 517-525.

Givskov, M., Olsen, L. \& Molin, S. (1988). Cloning and expression in Escherichia coli of the gene for extracellular phospholipase A1 from Serratia liquefaciens. J Bacteriol 170, 5855-5862.

Hall, B. G., Yokoyama, S. \& Calhoun, D. H. (1983). Role of cryptic genes in microbial evolution. Mol Biol Evol 1, 109-124.

luchi, S. \& Lin, E. C. C. (1993). Adaptation of Escherichia coli to redox environments by gene expression. Mol Microbiol 9, 9-15.

Jacobson, G. R. \& Saraceni-Richards, C. (1993). The Escherichia coli mannitol permease as a model for transport via the bacterial phosphotransferase system. J. Bioenerg Biomembr 25, 621-626.

Jacoby, J., Hollenberg, C. P. \& Heinisch, J. J. (1993). Transaldolase mutants in the yeast Kluyveromyces lactis provide evidence that glucose can be metabolized through the pentose phosphate pathway. Mol Microbiol 10, 867-876.

Jones, D. H. A., Franklin, C. H. \& Thomas, C. M. (1994). Molecular analysis of the operon which encodes the RNA polymerase sigma factor $\sigma^{54}$ of Escherichia coli. Microbiology 140, 1035-1043.

Kohlbrecher, D, Eisermann, R. \& Hengstenberg, W. (1991). Staphylococcal phosphoenolpyruvate-dependent phosphotransferase system: molecular cloning and nucleotide sequence of the Staphylococcus carnosus ptsI gene and expression and complementation studies of the gene product. J Bacteriol 174, 2208-2214.

Kornberg, H. L. (1990). Fructose transport by Escherichia coli. Pbil Trans $\mathrm{R}$ Soc 326,505-513.

Kyte, J. \& Doolittle, R. F. (1982). A simple method for displaying the hydropathic character of a protein. J Mol Biol 157, 105-132.

LiCalsi, C., Crocenzi, T. S., Freire, E. \& Roseman, S. (1991). Sugar transport by the bacterial phosphotransferase system: structural and thermodynamic domains of Enzyme I of Salmonella typhimurium. $J$ Biol Chem 266, 19519-19527.

Lu, Z. \& Lin, E. C. (1989). The nucleotide sequence of Escherichia coli genes for L-fucose dissimilation. Nucleic Acids Res 17, 4883-4884.

Mallinder, P. R., Pritchard, A. \& Moir, A. (1992). Cloning and characterization of a gene from Bacillus stearothermophilus var. nondiastaticus encoding a glycerol dehydrogenase. Gene 110, 9-16.

Matsuoka, M., Ozeki, Y., Yamamoto, N., Hirano, H., KanoMurakami, Y. \& Tanaka, Y. (1988). Primary structure of maize pyruvate, orthophosphate dikinase as deduced from cDNA sequence. J Biol Chem 263, 11080-11083.

Niersbach, M., Kreuzaler, F., Geerse, R. H., Postma, P. W. \& Hirsch, H. J. (1992). Cloning and nucleotide sequence of the Escherichia coli K-12 pps $A$ gene, encoding PEP synthase. Mol \& Gen Genet 231, 332-336.
Parker, L. L. \& Hall, B. G. (1990). Characterization and nucleotide sequence of the cryptic cel operon of Escherichia coli K12. Genetics 124, 455-471.

Pearson, W. R. \& Lipman, D. J. (1988). Improved tools for biological sequence comparison. Proc. Natl Acad Sci USA 85, 2444-2448.

Pelliccione, N., Jaffin, B., Sobel, M. E. \& Krulwich, T. A. (1979). Induction of the phosphoenolpyruvate: hexose phosphotransferase system associated with relative anaerobiosis in an obligate aerobe. Eur J Biochem 95, 69-75.

Peterson, S. N., Hu, P. C., Bott, K. F. \& Hutchison, C. A. (1993). A survey of the Mycoplasma genitalium genome by using random sequencing. J Bacteriol 175, 7918-7930.

Plunkett, G., III, Burland, V., Daniels, D. L. \& Blattner, F. R. (1993). Analysis of the Eschericbia coli genome. III. DNA sequence of the region from 87.2 to 89.2 minutes. Nucleic Acids Res 21, 3391-3398.

Pocalyko, D. J., Carroll, L. J., Martin, B. M., Babbitt, P. C. \& Dunaway-Mariano, D. (1990). Analysis of sequence homologies in plant and bacterial pyruvate phosphate dikinase, Enzyme I of the bacterial phosphoenolpyruvate:sugar phosphotransferase system and other PEP-utilizing enzymes. Identification of potential catalytic and regulatory motifs. Biochemistry 29, 10757-10765.

Postma, P., Lengeler, J. \& Jacobson, G. R. (1993). Phosphoenolpyruvate:carbohydrate phosphotransferase systems of bacteria. Microbiol Rev 57, 543-594.

Powell, B. S., Court, D. L., Inada, T., Nakamura, Y., Michotey, V., Cui, X., Reizer, A., Saier, M. H., Jr \& Reizer, J. (1995). Novel proteins of the phosphotransferase system encoded within the rpoN operon of Escherichia coli. EnzymeIIA ${ }^{\text {Ntr }}$ affects growth on organic nitrogen and the conditional lethality of an era ${ }^{\text {ts }}$ mutant. J Biol Chem (in press).

Pries, A., Priefert, H., Kruger, N. \& Steinbuchel, A. (1991). Identification and characterization of two Alcaligenes eutrophus gene loci relevant to the poly ( $\beta$-hydroxybutyric acid)-leaky phenotype which exhibits homology to pts $H$ and ptsI of Escherichia coli. $J$ Bacteriol 173, 5843-5853.

Prior, T. I. \& Kornberg, H. L. (1988). Nucleotide sequence of fru $A$, the gene specifying enzyme $\mathrm{II}^{\text {fru }}$ of the phosphoenolpyruvatedependent sugar phosphotransferase system in Escherichia coli K12. $J$ Gen Microbiol 134, 2757-2768.

Reizer, A. \& Reizer, J. (1994). Progressive multiple alignment of protein sequences and the construction of phylogenetic trees. In Methods in Molecular Biology: Computer Analysis of Sequence Data, Part II, pp. 319-325. Edited by A. M. Griffin \& H. G. Griffin. Totowa, NJ: Humana Press.

Reizer, A., Deutscher, J., Saier, M. H., Jr \& Reizer, J. (1991a). Analysis of the gluconate (gnt) operon of Bacillus subtilis. Mol Microbiol 5, 1081-1089.

Reizer, A., Pao, G. M. \& Saier, M. H., Jr (1991b). Evolutionary relationships among the permease proteins of the bacterial phosphoenolpyruvate:sugar phosphotransferase system. Construction of phylogenetic trees and possible relatedness to proteins of eukaryotic mitochondria. J Mol Evol 33,179-193.

Reizer, J., Reizer, A., Saier, M. H., Jr \& Jacobson, G. R. (1992). A proposed link between nitrogen and carbon metabolism involving protein phosphorylation in bacteria. Protein Sci 1, 722-726.

Reizer, J., Hoischen, C., Reizer, A., Pham, T. N. \& Saier, M. H., Jr (1993). Sequence analyses and evolutionary relationships among the energy-coupling proteins Enzyme I and HPr of the bacterial phosphoenolpyruvate: sugar phosphotransferase system. Protein Sci 2, 506-521.

Reizer, J., Michotey, V., Reizer, A. \& Saier, M. H., Jr (1994a). Novel phosphotransferase system genes revealed by bacterial genome 
analysis: unique, putative fructose- and glucoside-specific systems. Protein Sci 3, 440-450.

Reizer, J., Reizer, A., Kornberg, H. L. \& Saier, M. H., Jr (1994b). Sequence of the fruB gene of Escherichia coli encoding the diphosphoryl transfer protein (DTP) of the phosphoenolpyruvate: sugar phosphotransferase system. FEMS Microbiol Lett 118, 159-162.

Rodel, W., Plaga, W., Frank, R. \& Knappe, J. (1988). Primary structures of Escherichia coli pyruvate formate-lyase and pyruvate formate-lyase-activating enzyme deduced from the DNA nucleotide sequences. Eur J Biochem 177, 153-158.

Romano, A. H. \& Saier, M. H., Jr (1992). Evolution of the bacterial phosphoenolpyruvate: sugar phosphotransferase system. I. Physiologic and organismic considerations. In The Evolution of Metabolic Function, pp. 171-204. Edited by R. P. Mortlock. Boca Raton, FL: CRC Press.

Rosche, E. \& Westhoff, P. (1990). Primary structure of pyruvate, orthophosphate dikinase in the dicotyledonous $\mathrm{C}(4)$ plant Flaveria trinervia. FEBS Lett 273, 116-121.

Saffen, D. W., Presper, K. A., Doering, T. L. \& Roseman, S. (1987). Sugar transport by the bacterial phosphotransferase system. Molecular cloning and structural analysis of the Escherichia coli $p t s H$, ptsI, and crr genes. J Biol Chem 262, 16241-16253.

Saier, M. H., Jr (1977). Bacterial phosphoenolpyruvate:sugar phosphotransferase systems: structural, functional, and evolutionary interrelationships. Bacteriol Rev 41, 856-871.

Saier, M. H., Jr \& Reizer, J. (1992). Proposed uniform nomenclature for the proteins and protein domains of the bacterial phosphoenolpyruvate: sugar phosphotransferase system. J Bacteriol 174, 1433-1438.

Saier, M. H., Jr \& Reizer, J. (1994a). Computational analyses aiding identification and characterization of proteins, genes and operons. In Methods in Molecular Genetics. Edited by K. W. Adolph. Orlando, FL: Academic Press (in press).

Saier, M. H., Jr \& Reizer, J. (1994b). The bacterial phosphotransferase system: new frontiers 30 years later. Mol Microbiol 13,755-764.

Saier, M. H., Jr, Grenier, F. C., Lee, C. A. \& Waygood, E. B. (1985). Evidence for the evolutionary relatedness of the proteins of the bacterial phosphoenolpyruvate: sugar phosphotransferase system. $J$ Cell Biochem 27, 43-56.

Saier, M. H., Jr, Reizer, A., Pao, G. M., Wu, L.-F., Reizer, J. \& Romano, A. H. (1992). Evolution of the bacterial phosphoenolpyruvate: sugar phosphotransferase system. II. Molecular considerations. In The Evolution of Metabolic Function, pp. 171-204. Edited by R. P. Mortlock. Boca Raton, FL: CRC Press.

Sakai, H. \& Ohta, T. (1993). Molecular cloning and nucleotide sequence of the gene for pyruvate kinase of Bacillus stearothermophilus and the production of the enzyme in Escherichia coli. Evidence that the genes for phosphofructokinase and pyruvate kinase constitute an operon. Eur J Biochem 211, 851-859.

Sawers, G. \& Suppmann, B. (1992). Anaerobic induction of pyruvate formate-lyase gene expression is mediated by the ArcA and FNR proteins. J Bacteriol 174, 3474-3478.

Schaaff, I., Hohmann, S. \& Zimmermann, F. K. (1990). Molecular analysis of the structural gene for yeast transaldolase. Eur J Biochem
188, 597-603.

Sharp, P. M. \& Li, W. H. (1987). The codon adaptation index - a measure of directional synonymous codon usage bias, and its potential application. Nucleic Acids Res 15, 1281-1295.

Smith, D. W. (1988). A complete, yet flexible, system for DNA/ protein sequence analysis using VAX/VMS computers. Comput Appl Biosci 4, 212.

Sugiyama, J. E., Mahmoodian, S. \& Jacobson, G. R. (1991). Membrane topology analysis of the Escherichia coli mannitol permease by using a nested-deletion method to create $m t l A-p h o A$ fusions. Proc Natl Acad Sci USA 88, 9603-9607.

Sun, X., Harder, J., Krook, M., Jornvall, H., Sjoberg, B.-M. \& Reichard, P. (1993). A possible glycine radical in anaerobic ribonucleotide reductase from Escherichia coli: nucleotide sequence of the cloned $n r d D$ gene. Proc Natl Acad Sci US A 90, 577-581.

Sutrina, S. L., Chin, A. M., Esch, F. \& Saier, M. H., Jr (1988). Purification and characterization of the fructose-inducible HPr-like protein, FPr, and the fructose-specific Enzyme III of the phosphoenolpyruvate: sugar phosphotransferase system of Salmonella typhimurium. J Biol Chem 263, 5061-5069.

Titgemeyer, F., Reizer, J., Reizer, A., Tang, J., Parr, T. R., Jr \& Saier, M. H., Jr (1994). Nucleotide sequence of the region between $\mathrm{crr}$ and cys $M$ in Salmonella typhimurium: five novel ORFs including one encoding a putative transcriptional regulator of the phosphotransferase system. $D N A$ Sequence (in press).

Trach, K., Chapman, J. W., Piggot, P., Lecoq, D. \& Hoch, J. A. (1988). Complete sequence and transcriptional analysis of the spoOF region of the Bacillus subtilis chromosome. J Bacteriol 170, 4194 4208.

Truniger, V. \& Boos, V. (1994). Mapping and cloning of gld $A$, the structural gene of the Escherichia coli glycerol dehydrogenase. $J$ Bacteriol 176, 1796-1800.

Valerie, K., Stevens, J., Lynch, M., Henderson, E. E. \& De Riel, J. K. (1986). Nucleotide sequence and analysis of the 58.3 to $65.5-\mathrm{kb}$ early region of bacteriophage T4. Nucleic Acids Res 14, 8637-8654.

Varshney, U., Hutcheon, T. \& De Sande, J. H. (1988). Sequence analysis, expression, and conservation of Escherichia coli uracil DNA glycosylase and its gene (ung). J Biol Chem 263, 7776-7784.

Wagner, A. F. V., Frey, M., Neugebauer, F. A., Schafer, W. \& Knappe, J. (1992). The free radical in pyruvate formate-lyase is located on glycine-734. Proc Natl Acad Sci US A 89, 996-1000.

Wu, L.-F. \& Saier, M. H., Jr (1990). Nucleotide sequence of the fru $A$ gene encoding the fructose permease of the Rhodobacter capsulatus phosphotransferase system, and analyses of the deduced protein sequence. $J$ Bacteriol 172, 7167-7178.

Wu, L.-F., Tomich, J. M. \& Saier, M. H., Jr (1990). Structure and evolution of a multidomain, multiphosphoryl transfer protein: nucleotide sequence of the $f r u B(H I)$ gene in Rhodobacter capsulatus and comparisons with homologous genes from other organisms. $J$ Mol Biol 213, 687-703.

Yura, T., Mori, H., Nagai, H., Nagata, T., Ishihama, A., Fujita, N., Isono, K., Mizobuchi, K. \& Nakata, A. (1992). Systematic sequencing of the Escherichia coli genome: analysis of the 0-2.4 min region. Nucleic Acids Res 20, 3305-3308.

Received 12 July 1994; revised 19 October; accepted 11 November 1994. 